\title{
Operational Flammability Limits of Commercial Fuels - A Review
}

\author{
Tawfiq Al Mughanam \\ Dept. Chair, Dept. of Mechanical Engineering, King Faisal University, KSA
}

\begin{abstract}
This manuscript considers the operational flammability limits of commercial fuels used in the automotive and in the aviation industry. Commonly employed fuels are considered in this study. Understanding the flammability limits is an important aspect while choosing right fuel for a given application. An explosion of stored fuel or combustion system can be catastrophic and can create a serious impact to the society. Therefore, researchers while developing fuels and combustion systems must give considerable attention. This manuscript reviews the effect of vapour pressure and temperature on flammability of fuels and reviews the auto ignition and flash point temperature of fuels commonly seen in the automotive and in the aviation industry.
\end{abstract}

\section{Introduction}

Engine fuels must be sufficiently flammable to burn readily in engines. On the other hand, under storage conditions, the fuel must be inflammable. Ensuring that all fuels can be stored safely is a demanding requirement, perhaps particularly so, for aircraft fuels. On land, the storage condition temperatures can range between about $-10^{\circ} \mathrm{C}$ and $60^{\circ} \mathrm{C}$. Likewise, the pressures can range from $1.0 \mathrm{~atm}$ to perhaps $0.6 \mathrm{~atm}$. On aircraft, pressures and temperature can be as low as 0.05 atm and $-80^{\circ} \mathrm{C}$. The main engine fuels currently in use are gasoline, ethanol, often blended with gasoline, kerosene (for aircraft) and diesel. Any new fuels must be carefully evaluated over these pressure and temperature ranges.

This paper reviews the flammability of stored fuels. As reaction will occur in the gas phase, a primary parameter related to flammability is the vapour pressure. Fig. 1. shows the variation of vapour pressure with respect to temperature for gasoline.

For known air pressures, these values can give some approximate indication of relative flammabilities. With such data, gas phase composition or equivalence ratios can be found, most commonly when the fuel vapour is mixed with air. Lean and rich flammability limits can then be defined. Explosion is not possible for mixtures leaner than the lean limit, or richer than the rich limit. In measuring the flammability limit there must be no wall quenching effect, and the ignition must be strong enough to initiate the flame. In practice, these limits are often expressed in terms of the temperature and pressure for mixtures with air.

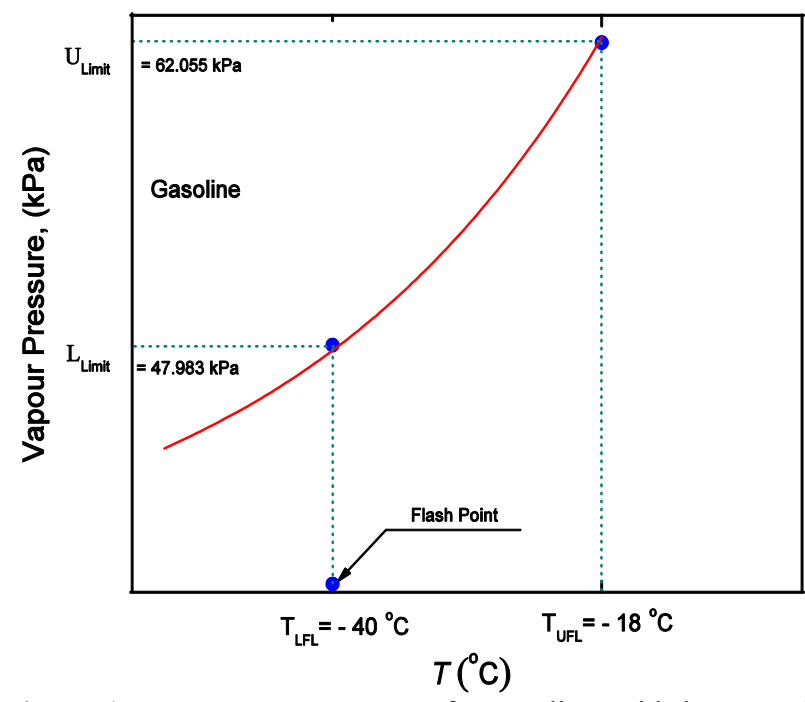

Figure 1. Vapour pressure curve for gasoline, with lower and upper flammability limit temperature, $T_{U F L}$ and, $T_{L F L}$ [1]

The temperature at the lean, or lower, flammability limit is indicated by $T_{L F L}$ in Fig. 1. Above this temperature in the regime of flammability, the concentration of fuel increases until the rich, or upper flammability limit, $T_{U F L}$ is attained. Lean $(\mathrm{L})$ and rich $(\mathrm{R})$ temperature limits at atmosphere pressure are shown in Fig. 2 for five different commercial fuels. It can be seen that at $25^{\circ} \mathrm{C}$ only ethanol is flammable under normal storage conditions.

at temperature, $T_{u=298 \mathrm{~K} \text { and }} P=0.1 \mathrm{MPa}[1,2]$ 


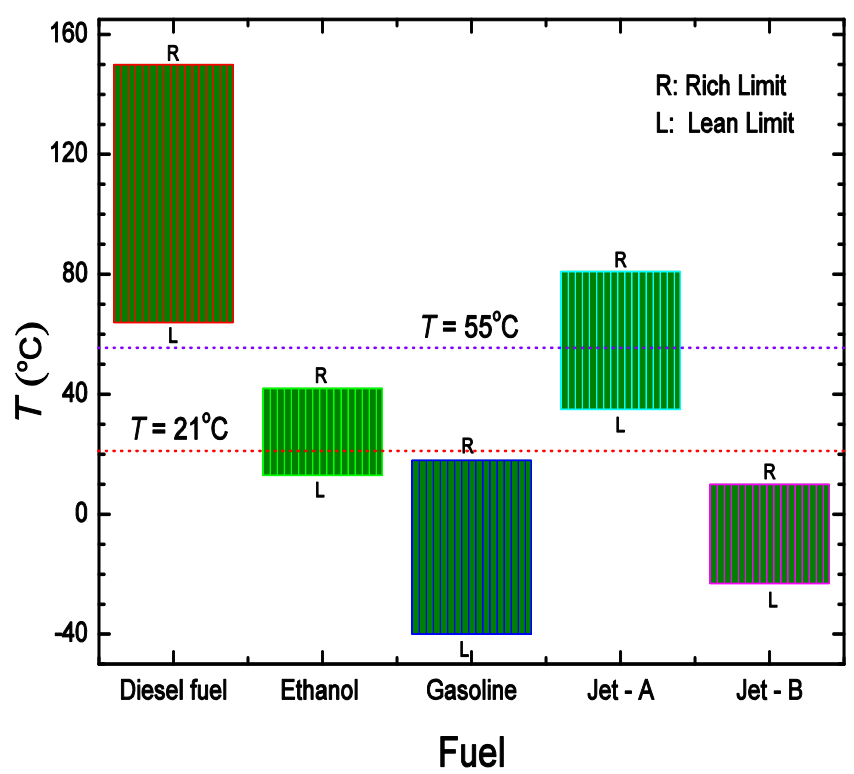

Figure 2. Flammability temperature limits for commercial fuels

Flammability limits can also be described by the flash point. This is the minimum temperature at which fuels evaporate and mix sufficiently with air, to ignite over the liquid surface. Another temperature employed is the auto ignition temperature, the temperature at which auto ignition occurs. This is very pressure dependent.

It is normally wise to assume an ignition source can be present and hence all mixtures should be stored under conditions outside the flammability limits. For example at atmospheric temperature and pressure, Fig. 2 shows, gasoline/air and Jet-B/air are beyond the rich limit, while diesel/air and Jet-A/air are usually beyond the lean limit. However, a minimum ignition energy must be supplied to the mixture to initiate an explosion.

\section{Aero Fuels}

Aviation fuel is a specialized type of petroleumbased fuel used to power aircraft. It is generally of a higher quality than fuels used in less critical applications, such as heating or road transport, and often contains additives to reduce the risk of icing or explosion due to high temperature, among other properties.

Most current commercial airlines and military aircraft use jet fuel for maximum fuel efficiency and lowest cost. Specific energy is the important criterion in selecting an appropriate fuel to power an aircraft. Much of the weight of an aircraft goes into fuel storage to provide the range, and more weight means more fuel consumption.

A wide range of equivalence ratios, pressures and temperatures are possible. Atmospheric turbulence and the aircraft motion can cause the liquid fuel to form a spray, vaporise, and spread through the available space, but demarcation of the two phases is not well defined [3]. Aircraft fuel tanks are of complex design with a variety of different devices for fuel distribution and venting. The combination of aircraft motion and fuel tank booster pumps create compositional changes due to fuel splash, and spray is distributed into the open spaces. In addition, the vapour phase composition changes with flight pressures and temperatures, and the wide range of fuel constituents with different boiling points can induce some fractional distillation [3]. Clearly, such changes will induce changes in the limits of flammability.

Aero fuels that meet the reviewed specification might be produced from different sources of crude oil and can have different compositions. Kerosene, the basis of jet fuels, is a distillation product of petroleum. It has many applications, but the use of raw kerosene in jet engines, without any fuel additive may not be prudent. There are two types of gas turbine aero engine fuel, Jet-A and Jet-B. These aviation kerosene's, like gasoline and diesel fuels, are made up of many constituent hydrocarbons. Molecules can contain between 4 and 20 carbon atoms, which are kerosene type jet fuels, and most commonly between about 8 and 16 atoms.

Jet- $\mathrm{B}$ is a mixture of gasoline and kerosene and is commonly used by civilian turbine-engines for its enhanced cold weather performance. It has a carbon number distribution between about 5 and 15 , with a lower flash point than Jet-A, refer Fig. 2. These types of fuels were developed commercially to meet military, commercial or private sector specifications [3]. USA has its own testing standards, while other parts of the world use the United Kingdom standards [3]. For Jet-A fuels flash points are between $37.78^{\circ} \mathrm{C}$ and $65.56^{\circ} \mathrm{C}$ while those for Jet-B fuels are between $-20.0^{\circ} \mathrm{C}$ and $-60.67^{\circ} \mathrm{C}$. A gas average for Jet-B has a value close to about $-45.56^{\circ} \mathrm{C}$. In comparison, lubricants, hydraulic fluids and engine oils have noticeably higher flash points.

Fig. 3 shows the variations of the temperature limits of flammability as a function of pressure for regular Jet-A and Jet-B fuels, respectively. This figure also shows the change in temperature, indicated by the NASA dotted line as the atmospheric pressure decreases with altitude, taken from the NASA website web location, (http://exploration.grc.nasa.gov/education/rocket/atmos.ht $\mathrm{ml})$.

Jet-A is more prone to form flammable vapour-air mixtures in tropical environments and at low altitudes, for example, during take off. Another factor is that oxygen dissolves in to the fuel before other gases, enhancing its ignitability [4].

Whilst, gasoline engine spark plugs require from 50 to $100 \mathrm{~mJ}$ to ignite the gaseous mixture, gas turbines require 12 Joules to ignite lean sprays in air $[4,5,6,7]$. When the temperature of the fuel becomes cooler at high altitude and low pressures, more energy is required to ignite the fuel-air mixture. 

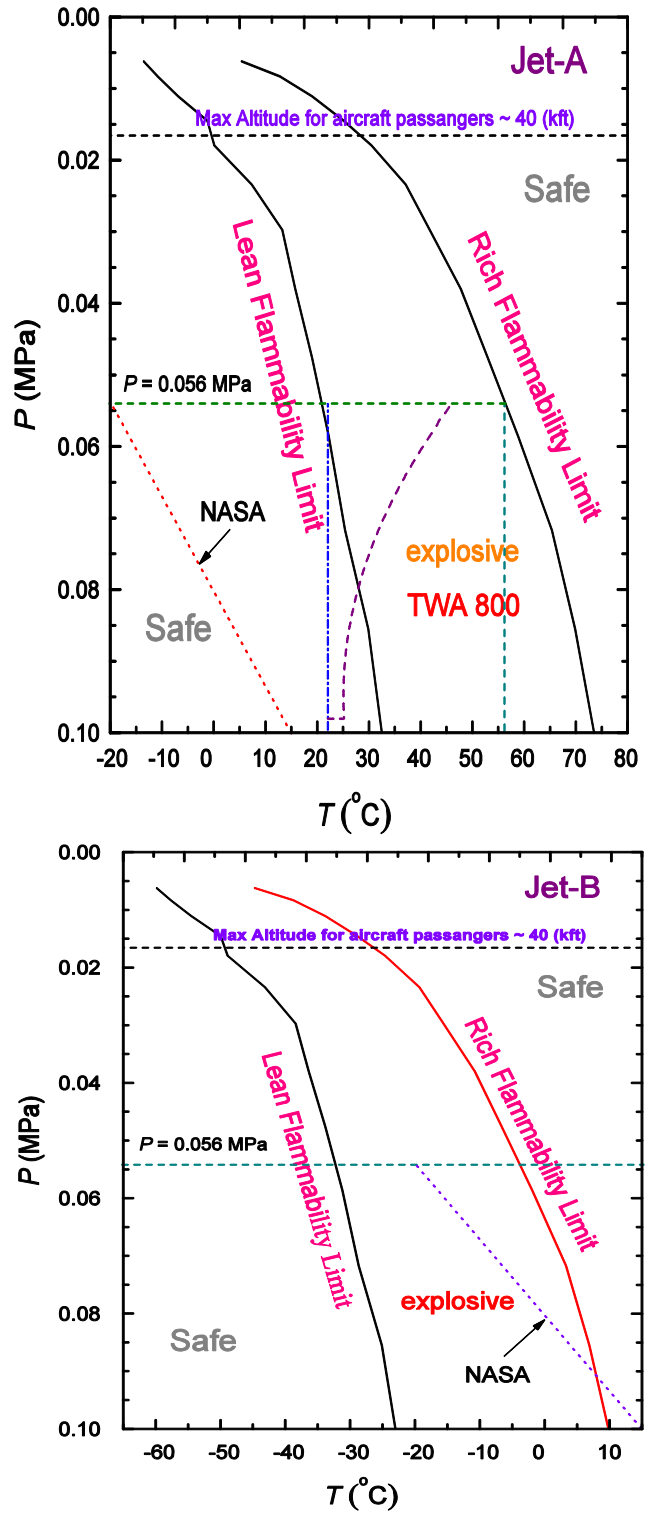

Figure 3. Pressure-temperature limits of flammability for Jet-A and Jet-B fuel in air

\section{Automotive Fuels}

Currently, the majority of motor vehicles worldwide are powered by gasoline or diesel. Other energy sources include ethanol, biodiesel, propane, compressed natural gas $(\mathrm{CNG})$, electric batteries charged from an external source, and hydrogen. The use of alternative fuels is increasing, especially in Europe.

Table 1. shows the volume $\%$ of air for both the UFL and LFL and the vapour pressure at $37.0^{\circ} \mathrm{C}$ for the main commercial fuels. Table 2. compares these same fuels with Jet fuels, in terms of flash point, auto ignition and flammability limit temperatures, at $P=0.1 \mathrm{MPa}$.

Tables 1 and 2, indicate that diesel fuel has the highest flash point. However, in terms of the auto-ignition temperature, ethanol has the highest value, followed by gasoline. Flammability tests conducted by Battelle [2] for pure diesel blended with different volumes ethanol, found that all the blends were almost identical to ethanol. All the blends had the same flash point and lower flammability limit as pure ethanol of about $12^{\circ} \mathrm{C}$, and with an upper flammability limit of about $42^{\circ} \mathrm{C}$.

In storage tanks, gasoline, as shown in Fig. 2, is flammable between -40 to $18^{\circ} \mathrm{C}$ compared with a range for diesel of 64 to $150^{\circ} \mathrm{C}$. Pumping diesel fuel into the tank causes a temperature increase, as with Jet-A. Measured temperatures inside the tank can be as high as $93^{\circ} \mathrm{C}$, exceeding the lower flammability limit [2].

The European Commission's (Energy and Transport) has defined the liquid fuels having a flash point $<21^{\circ} \mathrm{C}$ as class I highly flammable liquids. This includes gasoline, ethanol and Jet-B. Flash points $>21^{\circ} \mathrm{C}$ and $<55^{\circ} \mathrm{C}$ define class II fuels, for example, Jet-A. Flash points $>55^{\circ} \mathrm{C}$ and $<100^{\circ} \mathrm{C}$ define class III fuels [8].

Table 1. Upper and Lower flammability limits by volume of air and vapour pressure of commercial fuels at $P=0.1 \mathrm{MPa}$. Data from [1]

\begin{tabular}{|c|c|c|c|}
\hline Substance & $\begin{array}{l}\text { LFL in } \\
\% \text { by } \\
\text { Volume } \\
\text { of air }\end{array}$ & $\begin{array}{l}\text { UFL in } \\
\% \text { by } \\
\text { Volume } \\
\text { of air }\end{array}$ & $\begin{array}{l}\text { Vapour } \\
\text { Pressure at } \\
37.0^{\circ} \mathrm{C} \\
(\mathrm{kPa})\end{array}$ \\
\hline Diesel & 0.6 & 7.5 & 0.3 \\
\hline Ethanol & $3.3^{3}$ to & 19 & 17 \\
\hline $\begin{array}{l}\text { Gasoline } \\
\text { fuel (100 } \\
\text { Octane) }\end{array}$ & 1.4 & 7.6 & 65 \\
\hline
\end{tabular}

\begin{tabular}{|l|c|l|c|}
\hline Fuel & $\begin{array}{l}\text { Flash point } \\
\text { temperature, } \\
\left({ }^{\circ} \mathrm{C}\right)\end{array}$ & $\begin{array}{l}\text { Auto-ignition } \\
\text { temperature, } \\
\left({ }^{\circ} \mathrm{C}\right)\end{array}$ & $\begin{array}{l}\text { Flammability limits } \\
\text { temperature, }\left({ }^{\circ} \mathrm{C}\right)\end{array}$ \\
\hline Ethanol & 12.8 & 365 & 12 to 42 \\
\hline Gasoline & $<-40$ & 246 & -40 to 18 \\
\hline Diesel & $>62$ & 210 & 64 to 150 \\
\hline Jet Fuels (A and B) & $\begin{array}{l}>38 \text { for Jet-A } \\
\text { and } \\
<-23 \text { for } \\
\text { Jet-B }\end{array}$ & 210 & $\begin{array}{l}\text { Jet-A } 32 \text { to } 81 \text { and } \\
\text { Jet-B }-23 \text { to } 10\end{array}$ \\
\hline
\end{tabular}

\section{Discussion}

Flammability requires a fuel and oxygen together. Flammability limits are the boundaries of high and low fuel concentration, within which flammability is possible. The flammability characteristics of fluids are measured by standard laboratory tests. The procedures for these tests are rigorously defined to maximize repeatability of the measurements. Researchers have also performed tests 
of flammability properties of vehicle fluids in conditions more similar to those found in real-world vehicle fires. The results of both laboratory and real-world testing together provide the investigator with an understanding of the range of possible fire characteristics for the fluids of interest.

Understanding the flammability of fuels, the fuel conditions at different temperatures and pressures, ignition sources, etc. are very crucial while selecting fuels and designing combustion systems such as engines. As described before, the worst failure that could potentially occur from combustion systems and fuel storage systems is explosion, which could create a catastrophic effect on the mankind. This paper reviews certain commonly employed aviation and automotive fuels. Gasoline, ethanol, diesel, jet-A and jet-B fuels were considered in this review paper.

As an example, it must be recalled that the Trans World Airlines Flight 800 (TWA 800), a Boeing 747-131 from John F. Kennedy International Airport, exploded and crashed into the Atlantic Ocean near East Moriches, on July 17, 1996, 12 minutes after take-off, killing all 230 people on board. A full Investigation was conducted by the National Transportation Safety Board, NTSB and the probable cause of the accident was an explosion of the centre wing fuel tank, resulting from ignition of the flammable fuel/air mixture in the tank.

Going forward, as several new fuels are being developed, the fuel behaviour must be understood clearly at the storage and operational conditions. A thorough understanding on the flammability limits of fuels, their behaviour at various temperatures and pressures, the impact of air fuel ratios on flammability limits, accounting for flash point and auto ignition temperature of fuels are all certainly required while selecting fuels and while designing combustion systems.

\section{References}

1. McCormick, R. L., Parish, R., (2001), "Advanced Petroleum Based Fuels Program and Renewable Diesel Program - Technical barriers to Use of Ethanol in Diesel Fuel ", Final Report No.NREL/MP - 540 - 32674, National Renewable Energy Laboratory, U.S. Department of energy Laboratory.

2. Battelle, (1998), "A Flammability limit for ethanol/diesel blends", Final Report prepared by Battelle, Columbus, OH, USA.

3. Nestor, L.J., (1967), "Investigation of turbine fuel flammability within aircraft fuel tanks", Project No. 520 002 - 04X, Report No. DS - 67 - 7, Naval air propulsion test canter, aeronautical engine department, Naval base, Philadelphia, Pennsylvania 19112.

4. Dornheim, M. A., (1997a), "Industry Grapples With Fuel Tank Safety ", Aviation Week and Space Technology Press, Inc.

5. Dornheim, M. A., (1997b), "Fuel Ignites Differently In AirCraft, Lab Environments", Aviation Week and Space Technology Press, Inc.

6. Dornheim, M. A., (1997c), "Accidents Drive NTSB Push for New Rules", Aviation Week and Space Technology Press, Inc.

7. Dornheim, M. A., (1997d), "Airline Industry Takes Fresh Look at Inerting ", Aviation Week and Space Technology Press, Inc.

8. Chacartegui C.M, Lopez J.E.G, Alfonso F.S, Aakko P., Hamelinck C, Vossen G.V., Kattenwinkel H, (2007): Blending ethanol in diesel. BIOScope, Lot 3b, 10-12. 